\title{
Thiol anchoring and catalysis of gold nanoparticles at the liquid interface of thin-organic film-modified electrodes
}

\author{
Valentin Mirceski $^{\text {a,b,* }}$, Angela Aleksovska ${ }^{a}$, Biljana Pejova ${ }^{a}$, Vladimir Ivanovski ${ }^{a}$, Biljana Mitrova ${ }^{\text {a }}$, \\ Nikolina Mitreska ${ }^{a}$, Rubin Gulaboski ${ }^{\text {a,b }}$ \\ a Institute of Chemistry, Faculty of Natural Sciences and Mathematics, "Ss Cyril and Methodius" University, P.O. Box 162, 1000 Skopje, R. Macedonia \\ ${ }^{\mathrm{b}}$ Faculty of Medical Sciences, Goce Delcev University, Stip, R. Macedonia
}

\section{A R T I C L E I N F O}

Article history:

Received 29 October 2013

Received in revised form 19 November 2013

Accepted 21 November 2013

Available online 28 November 2013

Keywords:

Thin-organic-film electrodes

Liquid/liquid interface

Gold nanoparticles

\begin{abstract}
A B S T R A C T
The deposition of in-situ formed gold nanoparticles at the liquid/liquid (L/L) interface is studied by means of thin-organic-film-modified electrodes (TFE). The degree of ordering and aggregation of gold nanoparticles can be tuned by adding a lipophilic and hydrophilic thiol in the organic and aqueous phase, respectively. The ordered thiol-anchored gold nanoparticles exhibit pronounced catalytic effect toward electron-transfer reactions across the $\mathrm{L} / \mathrm{L}$ interface.
\end{abstract}

(C) 2013 Elsevier B.V. All rights reserved.

\section{Introduction}

Thin-organic-film-modified electrodes (TFE) [1], together with the droplet-electrodes (i.e. the three-phase electrodes) [2], are a useful tool for studying complex electrochemical processes where the electrode reaction is coupled with an ion-transfer across a $\mathrm{L} / \mathrm{L}$ interface. Their application ranges from determination of thermodynamic $[2,3]$ and kinetic parameters of ion $[4,5]$ and/or electron transfers $[1,6]$, mechanistic [7] and biomimetic studies of membrane processes [8], to bioelectroanalysis $[9,10]$. Besides, it has been demonstrated that TFE are an excellent scaffold for studying metal nanoparticle deposition at the $\mathrm{L} / \mathrm{L}$ interfaces [11], which is a unique environment due to its molecular smoothness [12]. Owing to the pronounced sensitivity of the voltammetric response of TFE to the properties of the liquid interfacial region, the aggregation of nanoparticles can be effectively examined by means of voltammetric techniques [11]. The study of metal particles synthesis and deposition at the L/L interface of TFE is justified for several reasons; e.g., it is a root for additional surface modification for advanced analytical applications [13,14], or it is a valuable approach for studying the catalytic properties of metal nanoparticles at the $\mathrm{L} / \mathrm{L}$ interface [15-18].

In the present communication we demonstrate that gold nanoparticles can be effectively anchored at the nitrobenzene/water (NB/W) interface by means of a hydrophobic and hydrophilic thiols added to the organic and aqueous phase, respectively. Thiol-anchored gold

\footnotetext{
* Corresponding author at: Institute of Chemistry, Faculty of Natural Sciences and Mathematics, "Ss Cyril and Methodius" University, P.O. Box 162, 1000 Skopje, Macedonia. E-mail address: valentin@pmf.ukim.mk (V. Mirceski).
}

nanoparticles effectively block the ion transfers, while significantly accelerate the heterogeneous electron transfers across the NB/W interface.

\section{Experimental}

All chemicals were of analytical grade purity. Decamethylferrocene (DMFC) was purchased from Fluka. Other chemicals (cysteine, tetrabutylammonium perchlorate $\left(\mathrm{Bu}_{4} \mathrm{NClO}_{4}\right), \mathrm{LiClO}_{4}$, thiophenol (PhSH), 1,1',4',1"-terphenyl-4-thiol $\left(\mathrm{Ph}_{3} \mathrm{SH}\right), \mathrm{K}\left[\mathrm{AuCl}_{4}\right], \mathrm{K}_{2}\left[\mathrm{PdCl}_{4}\right]$, $\mathrm{Hg}\left(\mathrm{NO}_{3}\right)_{2}, \mathrm{CuSO}_{4}, \mathrm{ZnSO}_{4}, \mathrm{~K}_{3}\left[\mathrm{Fe}(\mathrm{CN})_{6}\right]$, and $\left.\mathrm{H}_{2} \mathrm{O}_{2}\right)$ were Merck products. Nitrobenzene solution contained $50 \mathrm{mmol} / \mathrm{L} \mathrm{DMFC}$ and $0.1 \mathrm{~mol} / \mathrm{L}$ $\left(\mathrm{Bu}_{4} \mathrm{NClO}_{4}\right)$ as an organic electrolyte. For thiol experiments, $\mathrm{PhSH}$ or $\mathrm{Ph}_{3} \mathrm{SH}$ was added to $\mathrm{NB}$ at $0.1 \mathrm{mmol} / \mathrm{L}$, if not otherwise stated. A graphite rod (black graphite), GrafTech, UCAR SNC, La Lechere France ( $0.113 \mathrm{~cm}$ diameter) was a working electrode. After cleaning of the electrode surface ca. $0.3 \mu \mathrm{L}$ NB-solution was imposed, a thin film forming by spontaneous spreading of the solution. $0.1 \mathrm{~mol} / \mathrm{L}$ $\mathrm{LiClO}_{4}$ served as an aqueous electrolyte solution.

$\mathrm{An} \mathrm{Ag} / \mathrm{AgCl}$ ( $3 \mathrm{~mol} / \mathrm{L} \mathrm{KCl}$ ) was a reference, while Pt wire served as an auxiliary electrode. Cyclic voltammetry (CV) has been conducted at $\mu$ AUTOLAB III potentiostat/Galvanostat (Eco-Chemie, Netherlands).

Atomic forced microscopy (AFM) measurements were carried out using a scanning probe microscope, model SPM-9600 by Shimadzu. Imaging was performed in tapping mode and height, amplitude as well as phase images were recorded. Au deposits, prepared onto squared glass substrates ( $7 \mathrm{~mm} \times 7 \mathrm{~mm}$ ), were placed on a sample holder (15 nm diameter) and measured in $3 \mu \mathrm{m}, 2 \mu \mathrm{m}$ and $1 \mu \mathrm{m}$ scale with a scan rate of $1 \mathrm{~Hz}$ and resolution of 256 lines per scan direction. 
The measurements were done using silicon cantilever with the following characteristics: frequency of $320 \mathrm{kHz}$ and force constant of $42 \mathrm{~N} / \mathrm{m}$. A lot of different points on the sample surface were explored. The recorded images were just flattened and no additional processing was performed.

Raman spectra were recorded on a MicroRaman 300 (Horiba JobinYvon), employing a green Nd-Yag $532 \mathrm{~nm}$ laser line and a longdistance $\times 50$ lens (Olympus) objective. The maximum unfiltered power on the sample was $1.08 \mathrm{~mW}$. The integration time was $60 \mathrm{~s}$, for the Raman shift from $100 \mathrm{~cm}^{-1}$ to $4000 \mathrm{~cm}^{-1}$. A diffraction grid with 1800 grooves $/ \mathrm{mm}$ was used.

\section{Results and discussion}

The metal deposition at the $\mathrm{L} / \mathrm{L}$ interface of TFE is a consequence of the spontaneous electron-transfer reaction between DMFC embedded in the organic phase and the corresponding metal ions in the aqueous phase, coupled with a corresponding ion transfer to maintain the charge neutrality of the two liquid phases (reaction (1)), as originally demonstrated by Cheng and Schiffrin [19]. The heterogeneous redox reaction (1) and the metal deposit are mainly localized at the $\mathrm{L} / \mathrm{L}$ interface affecting strongly its properties.

$n \operatorname{DMFC}(\mathrm{NB})+\mathrm{M}^{n+}(\mathrm{W})+n \mathrm{ClO}_{4}{ }^{-}(\mathrm{W})=\mathrm{M}(\mathrm{s})+n \mathrm{DMFC}^{+}(\mathrm{NB})+n \mathrm{ClO}_{4}{ }^{-}(\mathrm{NB})$

Commonly, in the absence of redox active species in the aqueous phase, the voltammetric response of TFE is owing to a complex electron-ion coupled electrochemical process (reaction (2)), where the electrode reaction of DMFC is coupled with a virtually simultaneous ion transfer across the NB/W interface $[2,4,5]$.

$\operatorname{DMFC}(\mathrm{NB})+\mathrm{ClO}_{4}{ }^{-}(\mathrm{W})=\mathrm{DMFC}^{+}(\mathrm{NB})+\mathrm{ClO}_{4}{ }^{-}(\mathrm{NB})+\mathrm{e}^{-}$

Moreover, for $\mathrm{DMFC} / \mathrm{ClO}_{4}^{-}$system, the kinetics of the overall electron-ion transfer reaction (2) is controlled by the rate of $\mathrm{ClO}_{4}^{-}$transfer $[4,5]$. For these reasons, the voltammetric response of TFE is particularly sensitive to all phenomena affecting the properties of the $\mathrm{L} / \mathrm{L}$ interface. In the presence of another redox species in the aqueous phase, the overall electrochemical reaction could additionally involve a heterogeneous electron-exchange reaction across the $\mathrm{L} / \mathrm{L}$ interface $[1,6]$.

In the course of the repetitive potential cycling the metal deposition is manifested as a decreasing of the voltammetric response (inset of Fig. $1 \mathrm{~A}$ ), as a consequence of the blocking of the $\mathrm{L} / \mathrm{L}$ interface and hindering the ion transfer. The role of the standard potential difference between the two redox reactants, as a main driving force of the reaction (1), was examined by testing a series of metal cations, such as $\mathrm{Au}^{3+}$, $\mathrm{Hg}^{2+}, \mathrm{Pd}^{2+}, \mathrm{Cu}^{2+}$, and $\mathrm{Zn}^{2+}$. For all ions with $E_{\mathrm{M}^{n+} / \mathrm{M}}^{\varnothing}>E_{\mathrm{DMFC}^{+} / \mathrm{DMFC}}^{\varnothing}$ $\left(\mathrm{Au}^{3+}, \mathrm{Hg}^{2+}, \mathrm{Pd}^{2+}, \mathrm{Cu}^{2+}\right.$, ) the decreasing of the response was observed (data not shown), implying an effective metal deposition. Only in the case of $\mathrm{Zn}^{2+}$ the voltammetric response was fully stable, implying no metal deposition as $E_{\mathrm{M}^{n+} / \mathrm{M}}^{\varnothing}<E_{\mathrm{DMFC}^{+} / \mathrm{DMFC}^{\circ}}^{\varnothing}$

As previously shown [12-14], the rate of the metal deposition and the morphology of the deposit depend on various factors, the most important being the reactant concentration ratio and the potential difference at the NB/W interface controlled by the partition of common $\mathrm{ClO}_{4}^{-}$ions. For gold deposition, the morphology and ordering of the particles can be controlled by a thiol anchoring from both sides of the L/L interface. Fig. 1A summarizes the results collected in the absence (curve 1 ) and the presence of thiols (curves 2 and 3 ) deliberately added in the organic phase. The figure represents the current decrease $\left(\Delta I_{p}\right)$ as a function of the potential cycle serial number, i.e., $\Delta I_{\mathrm{p}}=I_{\mathrm{p}, \mathrm{a}(n)}-I_{\mathrm{p}, \mathrm{a}(1)}$, where $I_{\mathrm{p}, \mathrm{a}(n)}$ and $I_{\mathrm{p}, \mathrm{a}(1)}$ are the anodic peak currents of the $n$-th and the first cyclic voltammogram. Hence, the peak current decreases in proportion to the progressive interface


(1)

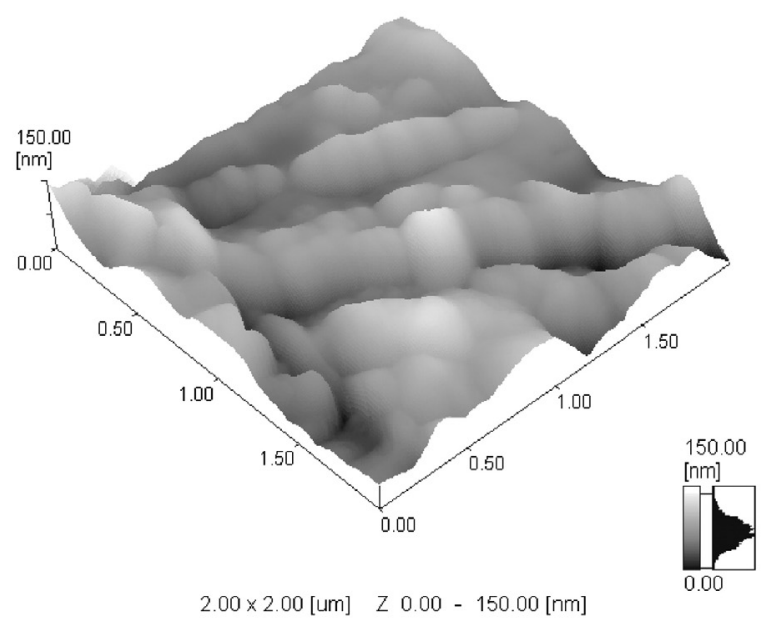

(2)

Fig. 1. (A) The decreasing of the anodic peak current $\left(\Delta I_{\mathrm{a}, \mathrm{p}}\right)$ as a function of the serial number of potential cycles recorded in the absence of thiol (1) and in the presence of $0.1 \mathrm{mmol} / \mathrm{L} \mathrm{PhSH} \mathrm{(2)} \mathrm{and} \mathrm{Ph}_{3} \mathrm{SH}$ (3) in the organic phase. The aqueous phase contained $1 \mathrm{mmol} / \mathrm{L} \mathrm{K}\left[\mathrm{AuCl}_{4}\right]$ and $0.1 \mathrm{~mol} / \mathrm{L} \mathrm{LiClO}_{4}$, while the organic phase contained $50 \mathrm{mmol} / \mathrm{L}$ DMFC and $0.1 \mathrm{~mol} / \mathrm{L} \mathrm{Bu}_{4} \mathrm{ClO}_{4}$. The inset shows repetitive cyclic voltammograms recorded in the absence of thiol. (B) AFM images of the gold deposit obtained in the absence of thiol (1) and in the presence of $1 \mathrm{mmol} / \mathrm{L} \mathrm{Ph}_{3} \mathrm{SH}$ in the organic phase (2). The gold deposition was ex-situ conducted by joining an aqueous and organic droplet of $0.5 \mu \mathrm{L}$ volume on a glass plate and AFM images and Raman spectra have been taken after complete evaporation of the solvents. (C) Raman spectra of: (a) neat $\mathrm{Ph}_{3} \mathrm{SH}$, (b) bare Au deposit, (c) glass on which the samples are deposited, (d) Au modified with $\mathrm{Ph}_{3} \mathrm{SH}$ and (e) Au modified with $\mathrm{Ph}_{3} \mathrm{SH}$ and cysteine. 

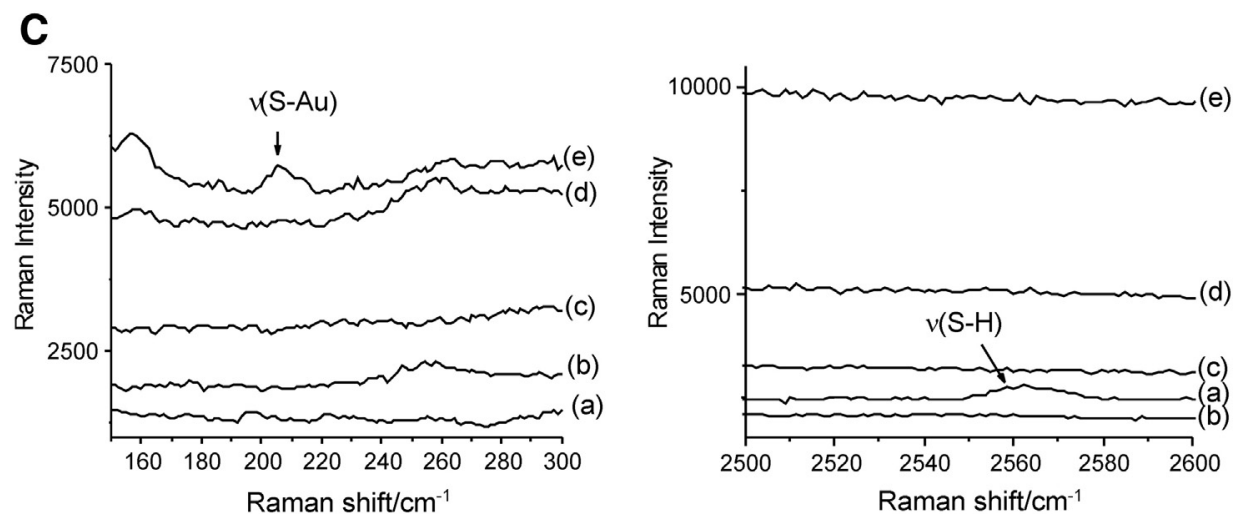

Fig. 1 (continued).

blocking with accumulated nanoparticles or formation of twodimensional aggregates at the NB/W, which hamper the ion transfer. Curves 2 and 3 correspond to the experiments with $\mathrm{PhSH}$ and $\mathrm{Ph}_{3} \mathrm{SH}$, the latter being significantly more lipophilic than the former. The data imply that the degree of interface blocking depends significantly on the presence and the lipophilicity of the thiol in the organic phase. The images made by AFM (Fig. 1B) imply that the blocking of the interface depends on the degree of ordering of gold nanoparticles. In the absence of thiol (panel (1) of Fig. 1B) randomly distributed particles and three-dimensional aggregates are formed, while in the presence of the thiol an obvious ordering of spherical particles is observed, rendering two-dimensional aggregation (panel (2) of Fig. 1B). Spectroscopic confirmation for thiol-modification has been performed by Raman spectroscopy. On Fig. 1C, (right panel) the $v(\mathrm{~S}-\mathrm{H})$ band with frequency of $2562 \mathrm{~cm}^{-1}$ is present only in the spectrum of the neat $\mathrm{Ph}_{3} \mathrm{SH}$ (Fig. 1C (a)), while absent in the spectra of the modified gold particles (Fig. 1C (d, e)), due to the cleavage of the $\mathrm{S}-\mathrm{H}$ bond and formation of the $\mathrm{S}-\mathrm{Au}$ bond.

The degree of ordering can be maximized by thiol-anchoring of gold nanoparticles from both sides of the liquid interface. To this purpose, besides modification with lipophilic thiol, the particles have been additionally stabilized with cysteine, hydrophilic thiol added to the aqueous phase. After the formation of gold nanoparticles at the liquid interface in the presence of lipophilic thiol, the electrode was carefully immersed into an electrolyte solution free of gold ions, but containing cysteine. After incubation of the modified electrode in the latter solution for $1 \mathrm{~h}$, the voltammetric response dramatically decreased, as illustrated by voltammograms in Fig. 2. During the incubation period no other gold nanoparticles could be formed; hence, the strong diminishing of the response is a consequence of ordering and aggregating of the preformed gold nanoparticles at the liquid interface, being in agreement with other findings [20]. This process is quite effective in the presence of the lipophilic $\mathrm{Ph}_{3} \mathrm{SH}$ thiol and cysteine, resulting in almost complete blocking of the liquid interface for the ion transfer reaction (curve 2 in Fig. 2C). A confirmation for formation of the $\mathrm{S}-\mathrm{Au}$ bond when $\mathrm{Ph}_{3} \mathrm{SH}$ and cysteine are chemisorbed on gold can be observed through the $v\left(\mathrm{~S}-\mathrm{Au}\right.$ ) band with maximum at $205 \mathrm{~cm}^{-1}$, clearly visible on Fig. $1 \mathrm{C}$ (e) (left panel) and partly visible on Fig. 1(d) (left panel). This assignment is according to the literature data [21] and references therein for the $v(\mathrm{~S}-\mathrm{Au})$ frequency position in Raman spectra of different metalalkane thiolates, appearing in the frequency range from $200 \mathrm{~cm}^{-1}$ to $240 \mathrm{~cm}^{-1}$.

Once immobilized, the gold nanoparticles are an effective catalyst toward the electron transfer across the liquid interface. To demonstrate this phenomenon, the heterogeneous redox reactions between DMFC(NB) and $\mathrm{H}_{2} \mathrm{O}_{2}(\mathrm{~W})$ and $\left[\mathrm{Fe}(\mathrm{CN})_{6}\right]^{3-}(\mathrm{W})$ have been studied (Fig. 3). Note that under such conditions, the electrochemical process at TFE couples the electrode reaction of DMFC/DMFC ${ }^{+}$ couple with the electron-exchange reaction across the $\mathrm{L} / \mathrm{L}$ interface, mediated by the gold deposit. These experiments are conducted by starting from $0.4 \mathrm{~V}$, corresponding to a reductive catalytic mechanism [11]. Though the details of the catalytic mechanism are not quite clear, it is plausible to assume that the immobilized gold nanoparticles act as bimetallic electrodes, adopting the potential of the liquid interface. The degree of the catalysis obviously depends on the degree of ordering and aggregating of the gold nanoparticles. In accord with the data in Fig. 2, the catalytic effect is the most pronounced when the particles are tightly anchored with $\mathrm{Ph}_{3} \mathrm{SH}$ and cysteine (Fig. 3). The peak currents of the voltammetric response increased for about $20 \mu \mathrm{A}$ in the presence of $1 \mathrm{mmol} / \mathrm{L}\left[\mathrm{Fe}(\mathrm{CN})_{6}\right]^{3-}$ (W) for a bare NB/W interface (Fig. 3A). In the presence of unordered gold nanoparticles, the corresponding current increase is $60 \mu \mathrm{A}$ (Fig. 3B), while after thiol-anchoring of the gold particles the peak current increase is for about $130 \mu \mathrm{A}$ (Fig. 3C), which is about six-
A



B

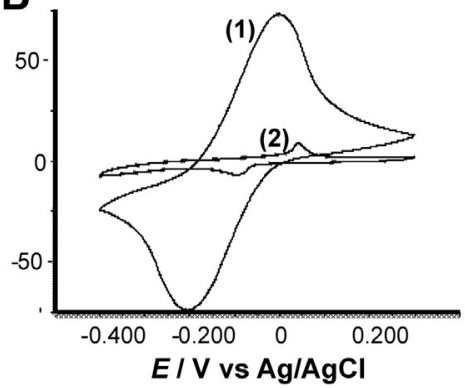

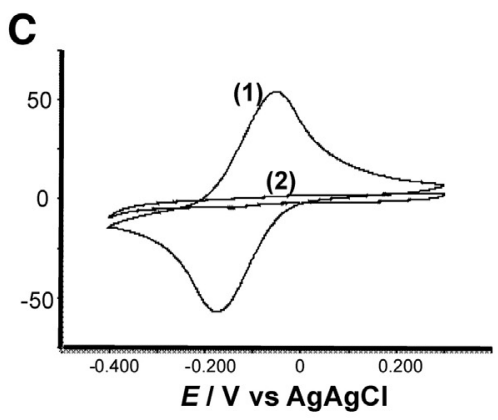

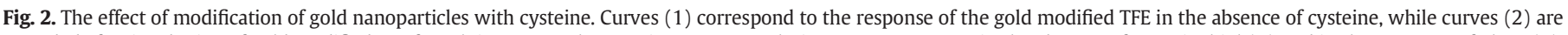

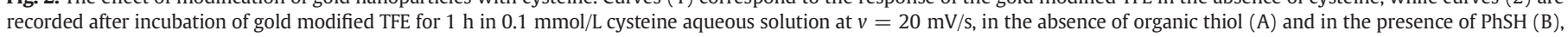
and $\mathrm{Ph}_{3} \mathrm{SH}(\mathrm{C})$. The other conditions are the same as for Fig. 1 . 

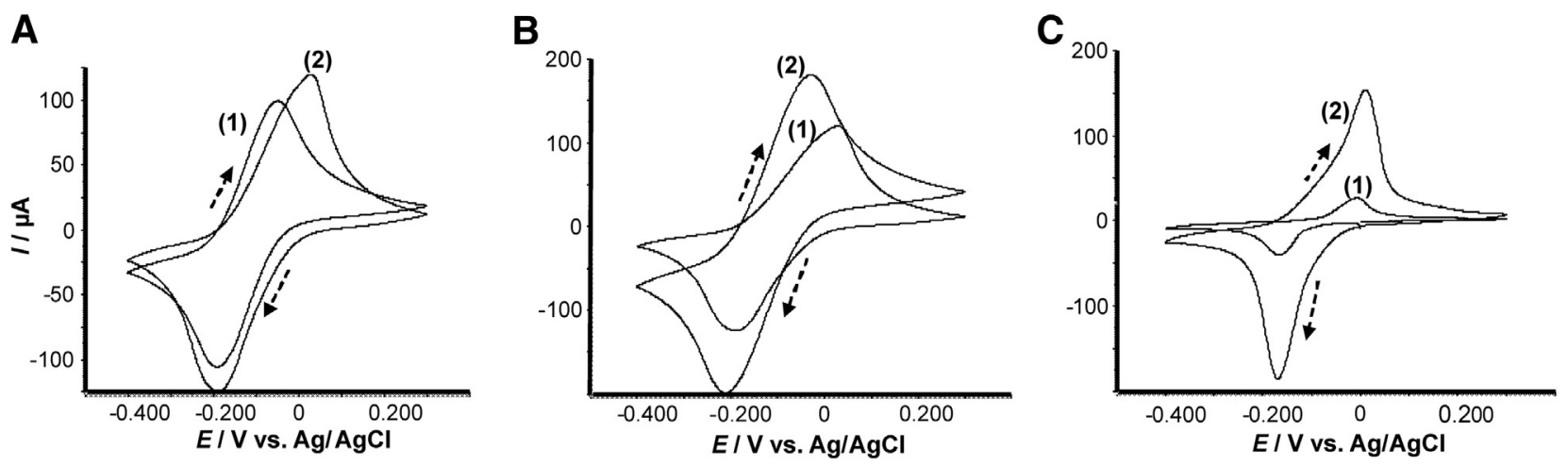

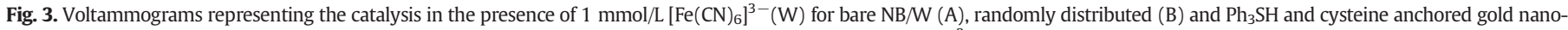

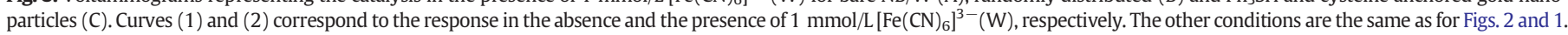

fold enhancement compared to the bare liquid interface. For corresponding experiments with $\mathrm{H}_{2} \mathrm{O}_{2}(\mathrm{~W})$, thiol-anchored gold nanoparticles caused about a five-fold increase of the current compared to the bare NB/W interface (data not shown), confirming the catalytic activity of the ordered gold nanoparticles.

\section{Conclusion}

We have demonstrated that in-situ prepared gold nanoparticles can be effectively immobilized at the $\mathrm{L} / \mathrm{L}$ interface of the TFE. The particles can be organized and ordered by thiol-anchoring from both sides of the interface. The degree of ordering and two-dimensional aggregation is proportional to the hydrophilicity and hydrophobicity of thiols added to the aqueous and organic phase, respectively. It is plausible to assume that the anchored nanoparticles at the polarized L/L interface acquire the potential of the interface, being transformed into bipolar electrodes that accelerate effectively the electron transfers across the $\mathrm{L} / \mathrm{L}$ interface.

\section{Acknowledgement}

Authors acknowledge Alexander von Humboldt foundation for the financial support from the Research Group Linkage Programme 3.4Fokoop-DEU/1128670, as well as the support of DAAD foundation through multilateral project "International Masters and Postgraduate Programme in Materials Science and Catalysis" (MatCatNet).

\section{References}

[1] C. Shi, F.C. Anson, J. Phys. Chem. B 102 (1998) 9850.

[2] F. Scholz, U. Schroder, R. Gulaboski, Electrochemistry of Immobilized Particles and Droplets, Springer, Berlin, 2005.

[3] K. Charreteur, F. Quentel, C. Elleouet, M. L'Her, Anal. Chem. 80 (2008) 5065.

[4] F. Quentel, V. Mirceski, M. L'Her, A. Pondaven, Electrochem. Commun. 7 (2005) 1122

[5] H. Deng, X. Huang, L. Wang, Langmuir 26 (2010) 19209.

[6] V. Mirceski, F. Quentel, M. L'Her, C. Elleouet, J. Phys. Chem. C 111 (2007) 8283.

[7] R. Gulaboski, E.S. Ferreira, C.M. Pereira, M.N.D.S. Cordeiro, A. Garau, V. Lippolis, A.F. Silva, J. Phys. Chem. C 112 (2008) 153.

[8] V. Mirceski, R. Gulaboski, I. Bogeski, M. Hoth, J. Phys. Chem. C 111 (2007) 6068.

[9] F. Quentel, K. Stankoska, O. Grupce, G. Jovanovski, V. Mirceski, Electrochem. Commun. 13 (2011) 1476.

[10] R. Gulaboski, C.M. Pereira, M.N.D.S. Cordeiro, I. Bogeski, F. Silva, J. Solid State Electrochem. 9 (2005) 469.

[11] V. Mirceski, R. Gulaboski, J. Phys. Chem. B 110 (2006) 2812.

[12] C.N.R. Rao, K.P. Kalyanikutty, Acc. Chem. Res. 41 (2008) 489.

[13] W.H. Binder, Angew. Chem. Int. Ed. 44 (2005) 5172.

[14] A.I. Campbell, R.A.W. Dryfe, M.D. Haw, Anal. Sci. 25 (2009) 307.

[15] H. Nagatani, S. Tonari, T. Shibata, T. Sagara, Electrochem. Commun. 13 (2011) 985.

[16] J.J. Nieminen, I. Hatay, P. Ge, M.A. Méndez, L. Murtomäki, H.H. Girault, Chem. Commun. 47 (2011) 5548.

[17] K. Bramhaiah, N.S. John, RSC Advances 3 (2013) 7765.

[18] S. Crossley, J. Faria, M. Shen, D.E. Resasco, Science 327 (2010) 68.

[19] Y. Cheng, D.J. Schiffrin, J. Chem. Soc. Faraday Trans. 92 (1996) 3865.

[20] S. Ferdous, D. Henneke, M.A. Ioannidis, J. Nanopart. Res. 13 (2011) 6579.

[21] G.J. Kluth, C. Carraro, R. Maboudian, Phys. Rev. B 59 (1999) R10449-R10452. 